\title{
TRAJETÓRIA DE JOVENS ADULTOS COM HIV: MEMÓRIAS DO AMBIENTE ESCOLAR
}

\author{
BARBARA REGINA FIRMINO*
}

\section{RESUMO}

Este artigo apresenta as memórias de jovens adultos com o vírus da imunodeficiência humana (HIV) pela transmissão vertical (desde o nascimento). Objetivos: identificar e investigar, a partir das memórias de jovens adultos, as experiências sobre o período da adolescência na escola. Método: A metodologia utilizada foi a qualitativa e uso da História Oral. Os dados foram coletados no Serviço de Extensão ao Atendimento de Pacientes HIV/Aids do Hospital das Clínicas da Faculdade de Medicina da Universidade de São Paulo, foram selecionados oito jovens adultos nascidos entre janeiro/1995 até janeiro/1998, de ambos os sexos, com HIV pela transmissão vertical e com o Ensino Médio concluído. Resultado: Pela narrativa dos entrevistados foi possível constatar como o silêncio acerca da condição de saúde ajustou-se ao meio educacional. A falta de informação a respeito do tema ainda impera e o estigma criado em torno da epidemia HIV/AIDS iniciada na década de 1980 ainda não foi superado. A história da vida desses jovens adultos com HIV faz parte da trajetória do combate à infecção do HIV/AIDS tanto no Brasil como no mundo, não somente no aspecto biológico, mas também nas esferas social, familiar e cultural que envolvem o cotidiano das

* Mestra em Educação. Dissertação: Trajetória de jovens adultos com HIV: memórias e experiências da adolescência no ambiente escolar. Programa de Pós-Graduação Stricto Sensu, Escola de Comunicação, Educação e Humanidades da Universidade Metodista de São Paulo. Orientador Prof. Dr. Marcelo Furlin. 
pessoas com HIV. Os entrevistados ressaltaram a necessidade da veiculação de informações na mídia para a prevenção do HIV e uma sólida atualização dos professores. As conclusões visam à interlocução da educação com a saúde na área formação dos professores.

Palavras-chave: Transmissão vertical. HIV. Memórias.

\begin{abstract}
This research presents the memories of young adults living with the human immunodeficiency virus (HIV), infected by vertical transmission (from birth). The objectives of the study were to identify and investigate, through young adults' memories, the experiences of positive HIV teenage students, infected by vertical transmission. Using the qualitative methodology of the Oral History, the survey was conducted at the Extension Service to HIV/AIDS Patients of the São Paulo University's Medicine College's General Hospital. Hence, eight young adults born between January/1995 and January/1998, of both sexes, with HIV through mother-to-child transmission and graduated in high school were selected to the individual interview. Result: through the interviewees' narratives, was possible understand how the silence about health conditions set in the educational environment. The lack of information on the subject still prevails and the stigma created around the HIV/AIDS epidemic, started in the 80 s, has not been overcome yet. The life paths of these young individuals living with the human immunodeficiency virus (HIV) are part of the trajectory of the fight against the HIV/AIDS infection either in Brazil as worldwide, not only in the biological aspect, but also in the social, family and cultural areas involving the daily lives of individuals with HIV. Respondents highlighted the need for media coverage serving for HIV prevention and strong update for teachers. The conclusions aim at the presentation of the study to dialogue between Education and Health in the teachers' training area.
\end{abstract}

Key-words: Vertical Transmission. HIV. Memories. 


\section{INTRODUÇÃO}

Este artigo é resultante da minha dissertação de mestrado e busca suscitar reflexões e propostas nas áreas da saúde e educação. A experiência que desenvolvi na área da saúde ao atender crianças, adolescentes e idosos no âmbito da saúde é, de fato, um dos grandes desafios que me impulsionaram ao aprimoramento pessoal e profissional. O contexto de cada atendimento, as peculiaridades das histórias de vida e a maneira como as pessoas, acometidas de alguma doença ou até mesmo de seus cuidadores, se predispuseram aos tratamentos e às orientações me parecem questões dignas de compartilhamento, principalmente para revelações de muitos dos silenciamentos que os jovens adultos com HIV, pela transmissão vertical, ${ }^{1}$ registraram no período escolar e o que esses mesmos jovens têm a relatar.

Para justificar esta pesquisa, diante da busca de referências e das opiniões dos jovens adultos, vale ressaltar o recente aumento do número de casos de infecção pelo HIV, desse público em particular (o jovem adulto). "Dados divulgados pelo Ministério da Saúde revelam que 827 mil pessoas vivem com HIV/AIDS no Brasil. Dessas, cerca de 112 mil não sabem que estão infectadas" (LABOISSIÈRE, 2016, p. 1).

Considerando as estatísticas apresentadas no Boletim Epidemiológico de 2016, ${ }^{2}$ é possível constatar que:

De 2007 até junho de 2016, foram notificados no Sinan 136.945 casos de infecção pelo HIV no Brasil. No mesmo período de 2007 a 2016, segundo sexo, foi notificado no

Denomina-se transmissão vertical do HIV a situação em que a criança é infectada pelo vírus da AIDS durante a gestação, o parto ou por meio da amamentação. Disponível em: <http://gavi.webnode.com.br/ preven $\%$ C3\%A7\%C3\%A3o/transmiss $\%$ C3\%A3o\%20vertical $\% 20$ do $\% 20$ hiv/>. Acesso em 29 jan. 2016.

2 Atualmente, o Departamento de DST, AIDS e Hepatites Virais lança dois Boletins Epidemiológicos ao ano. O primeiro, sempre em julho, apresenta dados referentes aos casos de hepatites virais no país. O segundo, e mais tradicional, revela e analisa informações referentes aos casos de AIDS em toda a população brasileira, inclusive em mulheres grávidas. Fonte: $<$ http:// www.AIDS.gov.br/pagina/boletim-epidemiologico>. Acesso em 21 fev. 2017. 
Sinan um total de 92.142 casos em homens e 44.766 casos em mulheres (BRASIL, 2016, p. 5).

Os especialistas consideram os números de infecções significativamente altos, visto que existem formas de prevenção. Contudo, os locais em que estão sendo divulgadas as informações e a maneira como elas alcançam o público tornaram-se um fato de preocupação para toda a sociedade, isto porque a doença, hoje considerada crônica, que é tratada por medicamentos disponíveis pelo Sistema Único de Saúde (SUS), ainda não tem cura e é tida como um problema de saúde pública e "epidemiológico, com o risco de transmissão e a propagação da doença” (LOPES, 2017, p. 1).

Ao pesquisar jovens adultos com HIV pela transmissão vertical, tendo como questão de pesquisa Como os jovens adultos com HIV discorrem sobre a trajetória pessoal, as memórias e as experiências da adolescência no ambiente escolar?, o que se almejou com as memórias apresentadas pelos jovens adultos com HIV foi o fato de que os relatos pudessem revelar as situações nas quais esses entrevistados receberam apoio e/ ou se mantiveram sigilo acerca do diagnóstico. Ainda buscamos informações que se consideram necessárias, sobretudo no que tange à necessidade de mudanças no âmbito escolar quanto à abordagem sobre sexualidade.

A esse respeito, muitos são os questionamentos que podem ser feitos pelos leitores da área da educação ou público diverso, ao refletir que, diante de um vasto horizonte de informações, ainda aconteça a transmissão vertical. Tal assunto desafia a todos os educadores sobre como contribuir com a formação de opiniões no meio social, seja no âmbito familiar, do trabalho, do lazer, da saúde, sobretudo da educação.

\section{O CENÁRIO (EM CONSTRUÇÃO) DO HIV/AIDS}

Um dos pontos positivos no combate ao HIV é a conquista na distribuição dos antirretrovirais para o tratamento - conforme assegura a Lei 9.313/1996 - o que possibilitou que as pessoas que vivem com HIV possam conseguir mais qualidade e expec- 
tativa de anos de vida e à necessidade de uma mobilização social para que a epidemia da AIDS não retorne.

Para Grangeiro (2016, p. 18), apesar da melhora de diversos indicadores, como o da "Estabilização da incidência ${ }^{3}$ do HIV", ainda é preciso observar outros pontos levantados pela comunidade científica, ativistas e gestores de saúde pública:

[...] quanto à magnitude que a epidemia de HIV e AIDS no Brasil atingiu em anos recentes seu patamar mais elevado, o que tem sido acompanhado por uma inflexão na tendência de estabilização da epidemia, notadamente nas novas gerações; a existência de um contingente expressivo de pessoas infectadas ainda desconhecedoras do status sorológicos; taxas de prevalência do HIV acima dos 5\% em algumas das regiões com alto grau de urbanização e em populações específicas.

O autor adverte que outras ações precisam ser estabelecidas para reduzir o número de pessoas com HIV, até porque o acesso aos antirretrovirais precisa também da aceitação por parte da pessoa que vive com HIV e que a mesma não desista de continuar no tratamento.

A atualização apresentada sobre a doença causada pelo Vírus da Imunodeficiência Humana (Human Immunodeficiency Virus - $\mathrm{HIV}^{4}$ ) e da AIDS $^{5}$ sugere que quanto maiores as condições de prevenção do conhecimento sobre o tratamento, tanto melhores serão as chances em redução da vulnerabilidade e do avanço da infecção.

3 Estabilização da Incidência do HIV compreende "a manutenção de importantes taxas de práticas sexuais protegidas nas relações com substantivo risco de infecção; e o aumento do número de pessoas em tratamento por antirretrovirais, com o consequente declínio das taxas de mortalidade por AIDS" (GRANGEIRO, 2016, p. 18).

4 Vírus da Imunodeficiência Humana (Human Immunodeficiency Virus - HIV). Disponível em: <http://www.AIDS.gov.br/pagina/o-que-e-hiv >. Acesso: 3 set. 2015.

5 AIDS - A AIDS é o estágio mais avançado da doença que ataca o sistema imunológico. Disponível em: <http://www.AIDS.gov.br/pagina/AIDS > . Acesso: 3 set. 2015. 
Inicialmente, as mulheres passaram a ser tratadas com a medicação, mas ainda eram desconhecidos os efeitos colaterais nos bebês e o modo de contágio - termo denominado como Transmissão Vertical. ${ }^{6}$ Nos estudos atuais, confirma-se que o aumento de crianças expostas ao vírus, pela transmissão vertical, ainda é a principal "forma de transmissão aos menores de 13 anos" (BRASIL, 2009, p. 2).

No âmbito da educação, em relação à saúde, foram elaborados os Parâmetros Curriculares Nacionais e os Temas Transversais, sendo que um deles considera a educação sexual. "São questões sociais significativas e urgentes e necessárias de serem trabalhadas, numa determinada sociedade, grupo, numa comunidade, e por serem significativas para estes grupos, devem ser tratadas na escola" (SESC TV, 2011, informação verbal ${ }^{7}$ ). Tal documento sugere a interface entre as disciplinas trazendo os assuntos atuais da sociedade na renovação do currículo.

\section{O ADOLESCENTE HIV POSITIVO E O CONTEXTO ESCOLAR}

A escola tem papel importante na vida das crianças e dos adolescentes, pois é nesse espaço que eles permanecem por um longo período de formação, ou seja, eles frequentam a escola entre a Educação Infantil, o Ensino Fundamental e o Ensino Médio (níveis da Educação Básica). Na vida escolar, a abordagem das vulnerabilidades, gênero e epidemia são aspectos discutidos no cotidiano. A literatura recente, que tece estudos nessa área, reitera que o apoio familiar precisa oferecer um suporte ao aluno e não delegar toda a formação a apenas aos profissionais da educação. Quando a criança ou o adoles-

6 Denomina-se transmissão vertical do HIV a situação em que a criança é infectada pelo vírus da AIDS durante a gestação, o parto ou por meio da amamentação. Ver: <http://saberviver.org.br/publicacoes/toda-gravida-soropositiva-para-o-hiv-deve-receber-azt-intravenoso-na-hora-do-parto/> Acesso em 29 nov. 2016.

7 Entrevista concedida por Ana Amélia Inue, sobre os temas transversais, ao Canal STV da rede SESC/SENAC no Programa Filhos. Disponível em: < https:// www.youtube.com/watch?v=n9fTgjMY7KY>. Acesso em 31 out. 2015. 
cente, que convive com HIV, encontra esse apoio, há chances favoráveis para alcançar um desenvolvimento mais saudável.

Os comportamentos dos adolescentes os tornam mais vulneráveis devido à expectativa de oportunidades experienciais e de consciência de limites. A partir de Brasil (2006a, p. 34):

Hoje sabemos que nossa fragilidade - ou nossa capacidade de enfrentar os desafios - depende de um conjunto integrado de aspectos individuais, sociais e institucionais. José Ricardo Ayres (2005) define a vulnerabilidade ao HIV e à AIDS como o conjunto de aspectos individuais e coletivos relacionados ao grau e modo de exposição à infecção e adoecimento pelo HIV e, de modo indissociável, ao maior ou menor acesso a recursos adequados para se proteger de ambos. Por isso, os comportamentos associados à maior vulnerabilidade não podem ser entendidos como uma decorrência imediata da vontade pessoal.

Tal consideração está relacionada ao poder de decisão e de maturidade que a pessoa tem diante das circunstâncias cotidianas, mas, essas são passíveis de exigir da pessoa discernimento e decisão sobre as vontades, o corpo, acerca da própria valorização enquanto pessoa e a condição em assumir a biossegurança, ao saber onde procurar orientação para os assuntos relacionados à sexualidade - como ir até um serviço de saúde.

Uma das propostas apresentadas pelo MEC, para manter o espaço de discussão cada vez mais frequente, está definida nos Parâmetros Curriculares Nacionais, ${ }^{8}$ "por meio da transversalidade, ${ }^{9}$ o que significa que tanto a concepção quanto

8 Os Parâmetros Curriculares Nacionais (PCN's) constituem um referencial de qualidade para a educação no Ensino Fundamental em todo o país. Para acessar os PCN's, o MEC disponibiliza o portal: < $\underline{\text { http://portal.mec.gov. }}$ br/seb/arquivos/pdf/livro01.pdf $>$ Acesso em 13 dez. 2016.

9 No âmbito dos PCNs, a transversalidade diz respeito à possibilidade de se estabelecer, na prática educativa, uma relação entre aprender conhecimentos teoricamente sistematizados (aprender sobre a realidade) e as questões da vida real e de sua transformação (aprender na realidade e da realidade). Não se trata de trabalhá-los paralelamente, 
os objetivos e conteúdos propostos por Orientação Sexual encontram-se contemplados pelas diversas áreas do conhecimento" (BRASIL, 1997a, p. 307).

O enfoque sugerido aos educadores pelos PCN's (BRASIL, 1997a, p. 325-326) é que:

[...] as informações sobre as doenças devem ter sempre como foco a promoção de condutas preventivas, enfatizando-se a distinção entre as formas de contato que propiciam risco de contágio daquelas que, na vida cotidiana, não envolvem risco algum.

Pelos dados aferidos no período de 2000 até 2016, houve um total de 15.250 de gestantes, na faixa etária entre 10 e 19 anos, diagnosticadas com HIV (BRASIL, 2016a). Se considerarmos que essa faixa etária está relacionada ao período que corresponde ao Ensino Fundamental e o término do Ensino Médio, observa-se que essas mulheres receberam informações sobre a infecção pelo HIV e tiveram noções acerca dos modos de prevenção, tanto na escola quanto por meio de recursos de saúde e da mídia.

\section{A COOPERAÇÃo ENTRE A EDUCAÇÃO, ÉTICA E BIOÉTICA}

Ao pensar em cooperação, encontramos em Moraes (2001, p. 20) uma observação peculiar sobre encontrar maneiras de superar a educação tradicional para que o ser humano, nas suas ações cotidianas individuais, sociais e de convivência, desenvolva uma interação mais condizente com a atualidade. É importante enfatizar que:

[...] se estamos preocupados em formar indivíduos autônomos, criativos, críticos, cooperativos, solidários e fraternos, mais integrados e harmoniosos, capazes de explorar o uni-

mas de trazer para os conteúdos e para a metodologia da área a perspectiva dos temas. Fonte: <http://www.educabrasil.com.br/ transversalidade/>. Acesso em 29 jan. 2017. 
verso de suas construções intelectuais, teremos de optar por um tipo de paradigma educacional diferente dos modelos convencionais e que por sua vez, foram influenciados por determinadas correntes psicológicas e filosóficas ancoradas num determinado paradigma adotado pela ciência.

A cooperação estabelecida entre a Educação, a Ética e a Bioética possibilita uma das mais importantes redes de conhecimentos e divulgação das reflexões da vida humana, e de todas as suas etapas e percalços. Segundo a autora, é necessário reconhecer que "[...] uma pedagogia reflexiva envolve um pensamento mais complexo [...], um pensamento que busca a totalidade, as interações, a integração para o encontro de soluções para os problemas e os desafios apresentados em nosso dia-a-dia" (MORAES, 2001, p. 27). Essa interação e integração que a Ética desenvolve nas relações pode ser reconhecida a partir dos Parâmetros Curriculares Nacionais (PCN's), que tratam de questões que: "[...] encontram-se a todo momento em todas as disciplinas" (BRASIL, 1997b, p. 63). Muitas vezes, a escola propicia reflexões que envolvem a ética, na discussão de situações que dizem respeito à vida cotidiana e o seu desenvolvimento.

A contribuição dos educadores no combate ao HIV representa uma das maiores expressões de recursos humanos existentes no Brasil, podendo favorecer a divulgação da prevenção e continuidade do tratamento.

\section{A PESQUISA DE CAMPO: TRAJETÓRIAS E MEMÓRIAS}

Ancorada na metodologia qualitativa, a pesquisa de campo teve como suporte metodológico a abordagem da História Oral, para obter as memórias dos jovens adultos com HIV positivo desde o nascimento e apresentar as narrativas da experiência que vivenciaram na escola no período da adolescência. A relevância do tema está pautada na necessidade em evidenciar que a área da Educação tem contribuição efetiva no auxílio às orientações acerca da prevenção e promoção de saúde, contribuindo com a diminuição das taxas da infecção do HIV. 
O campo de pesquisa foi o Serviço de Extensão ao Atendimento de Pacientes HIV/AIDS do Hospital das Clínicas da Faculdade de Medicina da Universidade de São Paulo (SEAP HCFMUSP), destinado ao ensino, estudos e assistência interdisciplinar. Para tanto, foi realizada a inscrição e encaminhado o projeto, que passou pela apreciação da Comissão de Ética para Análise de Projetos de Pesquisa do HCFMUSP (CAPPesq), do Programa de Pós-Graduação em Educação e na Coordenadoria de Pós-Graduação e Pesquisa da Universidade Metodista, Plataforma Brasil ${ }^{10}$ e a Comissão de Ética das moléstias infecciosas e parasitárias do Hospital das Clínicas da Faculdade de Medicina da Universidade de São Paulo.

Após a finalização do trâmite e a devida autorização, realizei a pesquisa com os entrevistados, que na ocasião eram pacientes do SEAP HCFMUSP. A partir da agenda dos atendimentos, foram feitos os contatos telefônicos para informar o propósito da pesquisa e a partir dos aceites, as entrevistas foram agendadas. A elegibilidade dos oito participantes contemplou as pessoas nascidas entre o mês de janeiro de 1995 até janeiro de 1998; de ambos os sexos; infectadas por transmissão vertical e que informaram ter o Ensino Médio concluído.

A seguir, a distribuição da identificação dos entrevistados nominados por letras (garantido o sigilo dos nomes a pedido dos próprios entrevistados).

10 A Plataforma Brasil é uma base nacional e unificada de registros de pesquisas envolvendo seres humanos para todo o sistema CEP/Conep. Disponível em: <http://aplicacao.saude.gov.br/plataformabrasil/login.jsf;jsessionid $=$ F45 91480CE152B3FD4CE42D8C87F5D32.server-plataformabrasil-srvipdf130>. Acesso em 5 fev. 2017. 
Quadro 1 - Perfil dos entrevistados

\begin{tabular}{|c|c|c|c|c|}
\hline $\begin{array}{c}\text { Entre- } \\
\text { vistado }\end{array}$ & Sexo & $\begin{array}{c}\text { Ida- } \\
\text { de }\end{array}$ & $\begin{array}{c}\text { Conclusão do } \\
\text { Ensino Médio }\end{array}$ & $\begin{array}{c}\text { Idade da } \\
\text { revelação } \\
\text { diagnóstica }\end{array}$ \\
\hline A & Masculino & 20 & Dez./2013 & 12 \\
\hline B & Feminino & 20 & Dez./2014 & 13 \\
\hline C & Feminino & 21 & Dez./2012 & 11 \\
\hline D & Feminino & 20 & Dez/.2013 & 08 \\
\hline E & - & - & - & - \\
\hline F & Masculino & 19 & Dez./2015 & 05 \\
\hline G & Masculino & 21 & Dez./2012 & 11 \\
\hline H & Masculino & 20 & Dez./2016 & 16 \\
\hline I & - & - & - & - \\
\hline J & Feminino & 20 & Dez./2013 & 6 \\
\hline
\end{tabular}

Fonte: a autora

As entrevistas totalizaram $3 \mathrm{~h} 35 \mathrm{~min}$. de gravação e foram realizadas após a assinatura do Termo de Consentimento, em sala de atendimento, sem interrupções e com o uso de gravador digital, seguindo o roteiro semiestruturado de questões. Foram reunidas dez categorias que versaram a respeito das memórias dos jovens adultos com HIV em relação ao período da adolescência na escola e a experiência do tratamento, estudo, relação familiar, entre outros aspectos. Neste artigo, são apresentadas três categorias e dois quadros elaborados a partir das narrativas e das percepções dos entrevistados.

\section{Categoria 1: discussão sobre DST/ HIV na escola}

Por meio das memórias, os jovens adultos com HIV evidenciaram uma preocupação com as explicações pontuais dos professores ao abordarem as doenças sexualmente transmissíveis, deixando os alunos sem os devidos esclarecimentos. Os entrevistados deixaram de culpabilizar os professores, mas destacaram que algo precisa ser feito para que os profissionais da Educação 
possam receber informações atualizadas sobre as DSTs. A seguir, alguns fragmentos das entrevistas.

[... abordavam de uma forma muito falha, mas tipo, eles não abordavam da forma que deveria. (Entrevistado A, informação verbal)

[...] a escola discutia? Bem pouco (Entrevistada B, informação verbal).

[...] conscientizava, ah! os professores, mas em sala às vezes, um ou outro dava opinião (Entrevistada C, informação verbal).

[...] Era bem relativo. No ensino médio a gente entrava um pouco mais nisso, sobre prevenção (Entrevistada D, informação verbal).

[...] porque os alunos não prestam atenção? Porque está na escola e está querendo bagunçar. Eles acham que não é importante, porque eles não tem, eu acho, né. Por exemplo: o professor começa a falar de HIV, falar, falar. Ah, mas, eu não tenho! Mas é bom você prestar atenção, você ter uma noção do que é e do que não é. Se você vai para escola é para você aprender, não para ficar fazendo desordem, é importante saber o que está acontecendo ao redor seu, né! (Entrevistado F, informação verbal).

[...] o professor chegava e explicava (Entrevistado G, informação verbal).

[...] é, mais no ensino médio, não lembro quais eram os professores, se falava no geral, igual para menino e para menina (Entrevistado J, informação verbal).

Nessa categoria os entrevistados "A", “B', "D" e "J" relataram que na adolescência as discussões realizadas na escola acerca do tema "doenças sexualmente transmissíveis" ocorreram especificamente no Ensino Médio. Os alunos realizavam pesqui- 
sas e faziam seminários para apresentar os resultados; também ressaltaram o que evidenciaram no comportamento da maioria dos colegas em sala de aula, que tratavam o assunto DST/HIV como irrelevante, visto que, sempre tinham uma piada, cuja expressão denominaram de "zoeira", "zoação".

Os entrevistados alertaram que os educadores precisam estar capacitados ao abordarem os assuntos relacionados à sexualidade, porque o silenciamento dos profissionais foi entendido como um despreparo e até certa omissão. As poucas discussões e apresentações entre os grupos de alunos estavam mais centradas em aspectos biológicos, deixando de acompanhar a importância do assunto diante da realidade vivenciada, por exemplo, dos próprios jovens adultos com HIV enquanto adolescentes e cientes de todo processo de tratamento, infecção e transmissão.

Segundo a observação dos entrevistados a respeito do silenciamento por parte dos educadores, na discussão sobre DST/ HIV na escola, Louro (1998, p. 46) considera que: “[...] o silêncio e o segredo significam uma tomada de posição ao lado de quem já detém a autoridade e a legitimidade"; o que deixa de contribuir para mudanças de opinião.

Os entrevistados ressaltaram a maneira como os colegas adolescentes trabalhavam com o tema doenças sexualmente transmissíveis e HIV/AIDS, o que causou uma indignação nos jovens adultos com HIV, ao rememorarem a falta de interesse, o desprezo e/ou a falsa impressão ao tratar de um assunto de fácil compreensão e tratamento. Outro ponto destacado pelos jovens foi a respeito dos aspectos sociais implicados no cotidiano de quem vive com HIV, que em momento algum foi mencionado, nas aulas que participaram, e que teria grande importância, pois, essa etapa da vida implicada nos relacionamentos, planejamento familiar, tratamento e todas as suas repercussões no estudo e no trabalho.

A precocidade do início da vida sexual entre 13 e 19 anos de idade acaba por não acompanhar a instrução formal (seja na escola, junto à família ou na comunidade) sobre os temas saúde e doença, associados aos aspectos culturais de submissão, e dessa forma, é a prevenção das DST/ HIV/AIDS que fica compro- 
metida aumentando a exposição para a infecção do HIV, ao se considerar que os parceiros são mais velhos, ou seja, tiveram muitas outras experiências sexuais (BRASIL, 2006b). Entre os anos de 2000 e 2014 foram 12.721 de gestantes, entre 10 a 19 anos de idade, diagnosticadas com HIV (BRASIL, 2014a) e esse motivo evidencia o possível aumento da transmissão vertical (BRASIL, 2006b, p. 14).

Outra observação apresentada por uma das entrevistadas foi a manifestação dos pais contra as explicações dos professores e a entrega de preservativos (camisinhas) na escola. Esses pais levaram à proibição dessa prática na escola.

Nesse sentido, a afirmação de Louro (1998, p. 46) considera que as "[...] dificuldades dos adultos em lidar com sua própria sexualidade acabam produzindo uma muralha de constrangimento e de omissão". Tal afirmativa dialogou com as experiências dos entrevistados, visto a dificuldade encontrada tanto na abordagem pelos professores, na oposição dos pais e a manifestação dos próprios colegas, ora interessados ora desfazendo-se da importância da discussão sobre DST HIV/AIDS.

\section{Categoria 2: Memórias da adolescência e preconceito}

Segundo a constatação dos entrevistados, o preconceito acontece quando as pessoas falam de assuntos que desconhecem e não procuram informações, e isso costuma ocorrer muito quando se fala do HIV. Seguem alguns fragmentos das entrevistas.

[...] a sociedade é muito preconceituosa - não vou chegar perto dela que tem HIV, falta de informação!!!! (Entrevistada D, informação verbal).

[...] acho que o preconceito das pessoas é muito grande, não só com o HIV, mas com outros problemas também (Entrevistado $H$, informação verbal).

[...] Preconceito, ficar virando a cara, fazendo piadinha (Entrevistada $B$, informação verbal). 
[...] a gente guarda para si. "manter sigilo é uma proteção para não vivenciarmos o desconforto e possível exclusão da família e dos amigos devido o preconceito que existe" (Entrevistado J, informação verbal).

[...] ela imaginava que se eu caísse ou a tocasse já estava passando (Entrevistada C, informação verbal).

[...] Você sabe que se souberem terá discriminação (Entrevistado $\mathrm{F}$, informação verbal).

Para Morin (2003, p. 19), a necessidade do esclarecimento sobre a vida resulta na "[...] incapacidade de conceber a complexidade da realidade antropo social na sua microdimensão (o ser individual) e na sua macrodimensão (o conjunto planetário da humanidade) conduziu a infinitas tragédias e conduz-nos à tragédia suprema".

Os jovens com HIV referiram que ainda encontram na sociedade pessoas que expressam ignorância, preconceito e menosprezam as pessoas que vivem com HIV. A maneira encontrada para superar o preconceito está na Educação e quanto mais diálogos forem estabelecidos, tanto maior a possibilidade de se dispor dos (pré)conceitos e superá-los.

Para Goffman (2004, p. 14), entender como individualmente manifestamos, expressamos e expomos a vida do outro passa por três tipos de estigma.

Em primeiro lugar, há as abominações do corpo - as várias deformidades físicas. Em segundo, as culpas de caráter individual, percebidas como vontade fraca, paixões tirânicas o não naturais, crenças falsas e rígidas, desonestidade, sendo essas inferidas a partir de relatos conhecidos de, por exemplo, distúrbio mental, prisão, vício, alcoolismo, homossexualismo, desemprego. Finalmente, há os estigmas tribais de raça, nação e religião, que podem ser transmitidos através da linhagem e contaminar por igual todos os membros da família. Em todos esses exemplos der estigma, entretanto, inclusive aqueles que os gregos tinham 
em mente, encontram-se as mesmas características sociológicas: um indivíduo que poderia ter sido facilmente recebido na relação social cotidiana possui um traço que pode-se impor à atenção e afastar aqueles que ele encontra, destruindo a possibilidade de atenção para outros atributos seus.

Ter a ciência dos três tipos de estigmas, que são disseminados e vivenciados no senso comum, possibilita reflexões da postura individual frente às situações que podem causar "estigma" contra alguém. O interesse pessoal em combater o preconceito é de fato fruto da vontade em não causar sofrimento a outra pessoa e também refletir como o meio social e cultural participam e influenciam esse processo. Para tanto, Castoriadis (1999, p. 45-46) esclarece que:

A verdadeira vontade não se refere à escolha de duas possibilidades pré-determinadas, mas a esse ato único, incoativo, no e pelo qual surgem novos possíveis e, ao mesmo tempo, o sujeito se dirige para eles. Tal sujeito não é uma realidade, é um projeto, em parte realizado pelos indivíduos e em parte, sobretudo, a ser realizado também em função de uma transformação que se refere não apenas aos seres humanos na sua singularidade, mas à sociedade em seu conjunto.

Ao considerar tal afirmação, podemos constatar que a vontade parte de uma escolha pessoal, principalmente em desenvolver a habilidade de mudar de opinião em busca de esclarecimentos, e como consequência tornar a sociedade melhor em relação à ideia de agregar e respeitar as pessoas.

As memórias que os entrevistados apresentaram sobre a experiência que trazem da adolescência com HIV e o preconceito são motivos singulares acerca da necessidade expressa em continuar contribuindo com esclarecimentos à sociedade com relação ao HIV/AIDS.

\section{Categoria 3: Apoio da equipe da escola}

$\mathrm{O}$ relato dos jovens adultos com HIV considerou a confiança que encontraram na direção escolar e a manutenção do 
vínculo emocional e de pertencimento com todos da escola. Três famílias recorreram à direção da escola para informações sobre o diagnóstico e o motivo das ausências dos entrevistados, e receberam o apoio esperado. Os entrevistados também informaram que não contaram para os demais profissionais da escola, entre eles os professores, pois consideraram não ter tido motivo. A seguir, alguns fragmentos das entrevistas.

[...] Tive professor que questionou meu atestado médico para abonar as faltas e pediu o código da doença, acho que era mais curiosidade, mas eu não disse nada para ninguém. Mantenho ainda algumas amizades do colégio, mas eles não sabem que convivo com HIV (Entrevistado A, informação verbal).

[...] Não contei para ninguém na escola (Entrevistada B, informação verbal).

Minha mãe avisou a Diretora e cuidavam muito bem de mim; se algum professor soube nunca me perguntaram nada. $\mathrm{O}$ maior apoio era na equipe de saúde, ainda mantenho a amizade (Entrevistada C, informação verbal).

[... Eu preferi não expor essa parte da minha vida na escola (Entrevistada D, informação verbal).

Várias vezes minha mãe recorreu às Diretoras das escolas no ensino fundamental e médio para explicar o motivo das minhas saídas para o tratamento, ressaltou a confiança que puderam ter nas profissionais (Entrevistado F, informação verbal).

[...] Ninguém na escola sabia. Acho que se soubessem me apoiariam (Entrevistado J, informação verbal).

Os entrevistados que informaram não terem buscado apoio da direção ou entre os professores da escola alegaram ter havido receio da discriminação. É relevante destacar que, ao tomar ciência da experiência dos jovens adultos com HIV, torna-se 
possível rever se é necessária uma mudança individual, frente ao silenciamento que porventura ocorra, quando nos deparamos com a necessidade de se trabalhar com o tema HIV.

A manifestação dos entrevistados corrobora com Souza, Demartini e Gonçalves (2016, p. XX) quando afirmam que:

Narrar é sem dúvida um exercício de empoderamento e de reaprendizagem que implica enfrentamentos diversos das sombras, dos medos, dos preconceitos, das marginalizações e dos silêncios e / ou táticas de publicização como uma ação de autonomização pelo ato de 'contar sua história', num diálogo constante entre narrativas, doenças crônicas e reconfiguração biográfica pelos 'deslimites da palavra'.

Para os autores, expor a própria história é um exercício de lapidação, quando a pessoa apresenta ao público o que mais lhe foi significativo na trajetória da vida e nesse contexto surgem as situações conflitantes, as superações e principalmente o valor da própria história, que poderá contribuir para que outras pessoas possam conhecer as peculiaridades de quem vive com HIV desde o nascimento.

A partir das narrativas, também foi possível a interpretação das considerações obtidas nas entrevistas e anotadas no diário de campo, e ainda a construção das impressões a partir de percepções tecidas diante dos entrevistados. Dessa maneira, foram elaborados quadros que serão apresentados na sequência.

\section{A PERCEPÇÃO DOS ENTREVISTADOS DA PESQUISA}

O uso do diário de campo, durante as entrevistas, possibilitou a elaboração dos quadros, com as percepções dos entrevistados da pesquisa. Para Queiroz (1983, p. 95), “[...] as anotações do caderno de campo do pesquisador podem trazer importantes contribuições, indicando qual o sentido registrado num detalhe ou gesto, que esclareça qual a orientação mais correta do significado". Dessa forma, os quadros apresentam o ponto alto da narrativa, do qual faz parte o momento mais entusiástico da entrevista, isso segundo o tema que lhes instigaram e o momen- 
to que demonstraram maior emoção e uma mensagem final do entrevistado de acordo com sua subjetividade plena de História.

Quadro 2 - A entrevistada "B"

"B", foi prestativa e atenciosa ao se expressar e ficou contente ao relembrar da adolescência na escola.

Ponto alto da narrativa: Quando considerou que o tabu que ainda impera entre os alunos faz que estes se manifestem com piadas ao invés de se inteirarem do assunto das DST/HIV/ AIDS e demostrarem espanto.

Momento de maior emoção: relembrar a ocasião que soube do diagnóstico quando ficou órfã de pai e mãe e da luta em manter vínculos de afeto e apoio dos irmãos.

Mensagem final da entrevistada: apreciar animais de estimação. Ser conciliadora com a família e participar de atividades comunitárias onde pode dar e receber apoio.

Fonte: a autora (dados da pesquisa)

Quadro 3 - A entrevistada "C"

"C", considerou que foi muito bom relembrar do período da adolescência na escola.

Ponto alto da narrativa: foi a explicação da entrevistada do período que os professores fizeram a abordagem das DST HIV/ AIDS no $4^{\circ}$. ano do ensino fundamental e a escola virou um alvoroço, pois os pais não aceitaram e infelizmente o moralismo prevaleceu e as discussões cessaram e as explicações dos professores também. A entrevistada considerou que as doenças crônicas no geral (HIV, Hipertensão, Diabetes) deveriam ser discutidas, pois são assuntos de saúde e de grande importância. Momento de maior emoção: C falou da escola e referiu que foi bom lembrar-se do que passou, disse que é um benefício relembrar.

Mensagem final da entrevistada: manter a determinação nos objetivos da vida e as amizades que cultivou desde a escola.

Fonte: a autora (dados da pesquisa) 
Ao apresentar as impressões dos entrevistados, foi possível compartilhar algo além dos registros da fonte oral, da transcrição das narrativas, com as observações do caderno de campo. O documento escrito, para Queiroz (1983 p. 86), “[...] não dispensa o cotejo com outros tipos de documentos, para aquilatar a veracidade ou o valor de suas revelações, englobando-se entre estes outros documentos o caderno de campo e as próprias recordações do pesquisador". A seguir, propõe-se uma tessitura entre as narrativas.

\section{AS CATEGORIAS EM PERSPECTIVA}

Foi possível constatar pelas narrativas dos entrevistados como o silêncio sobre a condição de saúde ajustou-se no meio educacional, de modo a manter o andamento das atividades em prejuízo da experiência das pessoas que vivem com HIV, no que tange à culpabilidade, ao medo de se expor, ao julgamento e à imposição social do sigilo. Vale ressaltar que os entrevistados concluíram o Ensino Médio entre os anos de 2012 e 2016 e alguns não encontraram apoio e/ou abertura para diálogos, salvo situações em que a família reportou-se à gestão escolar a fim de revelar o diagnóstico. A falta de informação ainda impera e não foi superado o estigma que se criou em torno da epidemia HIV/AIDS, iniciada na década dos anos de 1980.

Os jovens adultos com HIV, nascidos na década de 1990, fazem parte dos primeiros adolescentes que sobreviveram ao HIV pelo uso do medicamento e acompanhamento contínuo junto da equipe multiprofissional de Saúde. Outro ponto relevante é sobre a atenção à saúde da mulher gestante com HIV e as técnicas para evitar a transmissão no parto. As histórias de vida desses jovens adultos com HIV fazem parte da história de combate à infecção do HIV/AIDS no Brasil e no mundo - não somente no aspecto biológico, mas também a todo impacto social, familiar e cultural que envolve o cotidiano de todas as pessoas.

A pesquisa com os jovens adultos entrevistados gerou um aprofundamento sobre o conhecimento da experiência que apresentaram sobre viver com HIV para além das experiências da adolescência na escola. 


\section{CONSIDERAÇÕES FINAIS}

As ações de prevenção precisam do apoio da Educação, visto que, somente as ações desenvolvidas pela área da Saúde não dão conta das orientações de prevenção, e ainda que seja demonstrada a experiência das pessoas que vivem com HIV como maneira dos alunos terem outras possibilidades de reflexão, principalmente com o aumento das taxas de infecção. Que a falsa impressão pelo uso de medicamentos não seja motivo de abrir mão do autocuidado.

\section{ALGUMAS CONSIDERAÇÕES PARA A EDUCAÇÃO}

A partir das experiências e narrativas dos entrevistados, duas situações práticas foram evidenciadas com referência ao acolhimento das pessoas que vivem com HIV no ambiente escolar.

A primeira situação relacionou o apoio da direção ao aluno e à família. $\mathrm{O}$ apoio do diretor demonstrou que o profissional estava capacitado ou buscou recursos para lidar com tal informação. Alguns questionamentos podem ser levantados, como quando e onde o diretor obteve as informações necessárias para acompanhar o assunto HIV. Neste caso, proveniente de uma criança ou adolescente com HIV desde o nascimento. As indagações persistem. Os demais profissionais, no cumprimento da hierarquia administrativa da escola, também receberam a mesma orientação, atualização e capacitação?

A segunda questão refere-se aos docentes, que ao assumirem seus postos na escola, se chegam orientados sobre como abordar as Infecções Sexualmente Transmissíveis (IST) e o HIV em sala de aula. Independente do ano que o docente lecione, também é importante saber se em algum momento este recebeu atualização pela coordenação escolar.

No sentido de ampliar a reflexão, há ainda um questionamento: se as secretarias da educação, municipais ou estaduais, mantêm uma agenda para implementar a atualização junto aos seus profissionais. Se essas secretarias estiverem realizando atualizações, já contam com um número de multiplicadores de informação para veicular a realidade? Realidade essa que 
inclua além dos aspectos biológicos e também considere as questões sociais que abrangem o cotidiano das pessoas que vivem com o HIV.

Com referência a uma agenda nacional, o assunto HIV e ou as IST deveriam estar na pauta no Ministério da Educação. De fato, a abrangência também envolve o currículo dos cursos, com o compromisso das Instituições de Ensino Superior, bem como, os respectivos coordenadores das graduações, pós-graduações, mais especificamente os das áreas humanas.

No cotidiano da vida escolar, como tema "tabu", a sexualidade e tudo o que a envolve, necessita do devido esclarecimento por parte do profissional que é referência na formação de opinião, pois, ao se oportunizar discutir HIV e as IST, configura-se uma das instâncias de orientação sobre como preveni-las e tratá-las, e é uma maneira de conceder empoderamento aos estudantes sobre a realidade, acerca da vida individual e dos aspectos que demandam atenção, cuidado e tratamento, sem a necessidade da interrupção de projetos, para as pessoas que vivem com o HIV.

A importância de retornar ao assunto das IST e do HIV se faz urgente devido à ampliação do número de pessoas infectadas. Esta pesquisa usou os parâmetros relacionados no Estado de São Paulo e nos demais Estados brasileiros e promoveu as seguintes questões: como estão as discussões junto aos profissionais da educação? Estes conhecem as estatísticas atuais, regionais e os números que representam a infecção no público jovem?

A transmissão vertical do HIV é somente um dos aspectos que acometem crianças e adolescentes que vivem a experiência cotidiana em seu locus social e demandarão apoio por onde passarem. A transmissão horizontal (principalmente sexual) elevou as estatísticas e atinge os adolescentes e jovens adultos que precisam de uma atenção particular, para que o pleno exercício da cidadania aconteça e o espaço escolar possa possibilitar as informações necessárias.

Uma segunda situação relatada pelos entrevistados foi sobre o período completo do Ensino Fundamental e Ensino Médio em que não compartilharam o diagnóstico com a equipe 
escolar de um modo geral. Para reflexão, foram consideradas as perdas vivenciadas pelos entrevistados por não compartilharem o diagnóstico. Também foram abordadas as mudanças empreendidas na sala de aula com relação à postura, à reflexão sobre a maneira como se pré concebe e se julga a história do outro. Nesse sentido, outro aspecto contemplado foi como a escola poderia fazer a diferença na vida dos alunos, a partir da reflexão das histórias de vida que trazem a experiência da doença crônica e dar enfoque na vida e na expectativa dos planos futuros. Assim, a Bioética pode fazer parte do cotidiano dos educadores e oferecer possibilidades criativas para discussões de temas que fortaleçam os laços de empatia entre as pessoas e possam favorecer perspectivas que ultrapassem adversidades.

\section{REFERÊNCIAS}

BRASIL. Lei $\mathbf{N}^{\circ} \mathbf{9 . 3 1 3}$, de 13 de novembro de 1996. Distribuição gratuita de medicamentos aos portadores do HIV e doentes de AIDS, Brasília, 1996. Disponível em: < http://www.planalto.gov.br/ccivil_03/leis/L9313.htm>. Acesso em 28 nov. 2015.

Ministério da Justiça. Secretaria Nacional dos Direitos Humanos.

Direitos Humanos no Cotidiano: manual, 2. ed. Brasília, DF: Secretaria Nacional de Direitos Humanos; UNESCO, 1997a, 384p.

. Secretaria de Educação Fundamental. Parâmetros curriculares nacionais: terceiro e quarto ciclos do ensino fundamental. Ética. Brasília, DF: MEC; SEF, p. 44-98, 1997b. Disponível em: < http://portal.mec.gov.br/seb/ arquivos/pdf/livro082.pdf $>$. Acesso em 13 out. 2016.

. Secretaria de Educação Fundamental. Parâmetros curriculares nacionais: introdução aos parâmetros curriculares nacionais. Educação Fun-

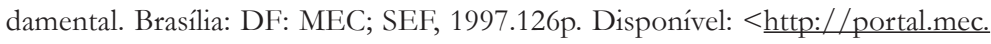
gov.br/seb/arquivos/pdf/livro01.pdf >. Acesso13/10/2016

Ministério da Saúde. Secretaria de Vigilância em Saúde. Saúde e prevenção nas escolas: guia para a formação de profissionais de saúde e de educação. Brasília, n. 76, 2006a, 160p. (série A - Normas e Manuais Técnicos). (Organizado por Ângela Donini, Maria Adrião, Marina Marcos Valadão e Vera Lopes.) Disponível em: < http://www.AIDS.gov.br/sites/default/files/ guia forma prof saude educacao.pdf> Acesso em 28 nov. 2015.

. Ministério da Saúde. Secretaria de Vigilância em Saúde. DST e Aids. Manual de rotinas para assistência de adolescentes vivendo com HIV/ Aids. Brasília: Ministério da Saúde, 2006b, 178p. (Organizado por Maria Letícia Santos Cruz, Lílian Day Hagel, Jorge Andrade Pinto e Cledy Eliana dos Santos.) Disponível em: < http://www.aids.gov.br/publicacao/2007/manual-de-rotinas- 
-para-assistencia-adolescentes-vivendo-com-hivaids >. Acesso em 10 jan. 2017. . Instituto de Pesquisa Econômica Aplicada. IPEA. 2014. Juventude levada $(\mathrm{em}) \mathbf{c}+\mathbf{o}+\mathbf{n}+\mathbf{t}=\mathbf{a}$ (demografia). Brasília, DF: IPEA, 2014a, 43p. Disponível em: < http://www.ipea.gov.br/agencia/images/stories/PDFs/130722 apresentacao2 juventudedemografia.pdf $>$. Acesso em 11 nov. 2016.

. Secretaria de Estado da Saúde de São Paulo. Boletim Epidemiológico: HIV AIDS. C.R.T. - DST/AIDS. C.V.E. ano V, n. 1, São Paulo, 2016a (período julho a dezembro de 2015 e janeiro a junho de 2016). Disponível em: <http://www.AIDS.gov.br/sites/default/files/anexos/publicacao/2016/59291/ boletim 20161 pdf 16375.pdf>. Acesso em 12 fev. 2017.

BRASIL. Boletim Epidemiológico. Disponível em: < http://www.AIDS.gov. br/pagina/boletim-epidemiologico >. Acesso em 12 fev. 2017.

BRASIL. O que é AIDS. Disponível em: < http://www.AIDS.gov.br/pagina/

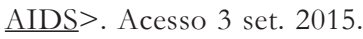

BRASIL. O que é HIV. Disponível em: < http://www.AIDS.gov.br/pagina/oque-e-hiv >. Acesso 3 set. 2015.

BRASIL. Plataforma Brasil. Disponível em: < http://aplicacao.saude.gov.br/ plataformabrasil $/$ login.jsf;jsessionid $=$ F4591480CE152B3FD4CE42D8C87F 5D32.server-plataformabrasil-srvipdf130>. Acesso em 5 fev. 2017.

CASTORIADIS, C. Para si e subjetividade. In: PENA VEGA, A.; NASCIMENTO, E. P. (Orgs.). O pensar complexo: Edgar Morin e a crise da modernidade. Rio de Janeiro: Garamond, 1999.

GOFFMAN, E. Estigma: Notas sobre a Manipulação da Identidade Deteriorada, 5. ed. Rio de Janeiro: LTC, 2004 (tradução de Márcia Bandeira de M. Leite Nunes, original de 1993).

GRANGEIRO, A. Da estabilização à reemergência: os desafios para o enfrentamento da epidemia de HIVAIDS no Brasil. In: ABIA. Mito vs Realidade: sobre a resposta brasileira à epidemia de HIV e AIDS em 2016. Rio de Janeiro: ABIA; UNITAID, p. 18-23, jul. 2016. Disponível em < $\underline{\text { http://abiAIDS.org.br/ }}$ wp-content/uploads/2016/07/Mito-vs-Realidade HIV-e-AIDS BRASIL2016. pdf $>$ Acesso em 10 jan. 2017.

GRUPO DE APOIO A VIDA. Transmissão Vertical do HIV. Disponível em: <: http://gavi.webnode.com.br/preven $\% \mathrm{C} 3 \% \mathrm{~A} 7 \% \mathrm{C} 3 \% \mathrm{~A} 3 \mathrm{o} /$ transmiss $\% \mathrm{C} 3 \% \mathrm{~A} 30 \% 20 \mathrm{vertical} \% 20 \mathrm{do} \% 20 \mathrm{hiv} />$ Acesso em 29 jan.2016.

LABOISSIÈRE, P. Brasil tem 827 mil vivendo com HIV; 112 mil não sabem que estão infectados. EBC agência Brasil. Brasília, p. 1, nov. 2016 (reportagem). Disponível em: <http://agenciabrasil.ebc.com.br/geral/noticia/2016-11/ brasil-tem-827-mil-vivendo-com-hiv-112-mil-nao-sabem-que-estao-infectados $>$. Acesso em 11 dez. 2016.

LOPES, H. V. Aids cresce $289 \%$ em 10 anos. São Bernardo do Campo: Diário do Grande ABC, mar. 2017 [on-line] (reportagem de Vanessa de Oliveira). Disponível em: < http://www.dgabc.com.br/Noticia/2515106/AIDS-cresce-289-em-10-anos >. Acesso em 12 mar. 2017. 
LOURO, G. L. Segredos e mentiras do currículo. Sexualidade e gênero nas práticas escolares. In: SILVA, L. H. (Org.). A escola cidadã no contexto da globalização, 5. ed. Petrópolis, RJ: Vozes, 1998.

MENEZES, E. T.; SANTOS, T. H. Verbete transversalidade. Dicionário Interativo da Educação Brasileira - Educabrasil. São Paulo: Midiamix, 2001. Disponível em: < http://www.educabrasil.com.br/transversalidade/>. Acesso em: 29 jan. 2017.

MORAES, M. C. O Paradigma Educacional Emergente, 7. ed. Campinas: Papirus, 2001.

MORIN, E. Introdução ao pensamento complexo, 2. ed. Lisboa: Ed. Instituto Piaget, 2003.

QUEIROZ, M. I. P. Variações sobre a técnica do gravador no registro da informação viva, 2. ed. São Paulo. CERVE/FFLCH/USP, 1983.

SESC TV. Entrevista concedida por Ana Amélia Inue: temas transversais. Canal STV na rede SESC/SENAC, dirigido por Sandra Regina Cacetari, 22m19s, 2011 (Programa Série Filhos). Disponível em: < $\underline{\text { https://www.youtube.com/ }}$ watch?v $=$ n9fTgjMY7KY $>$. Acesso em 31 out. 2015

SOUZA, E. C.; DEMARTINI, Z. B. F.; GONÇALVES, M. Gênero, diversidade e resistência de empoderamento, 1. ed. Curitiba, PR: CRV, 2016, 336p.

\section{SOBRE A AUTORA}

Prof. ${ }^{a}$ Bárbara Regina Firmino, Assistente Social especialista em Hospital Geral, Administração Hospitalar, Docência no ensino superior e Mestra em Educação. E-mail: barbara.firmino.brf@gmail.com

A dissertação completa encontra-se disponível em:

http://tede.metodista.br/jspui/bitstream/tede/1681/2/Barbara $\% 20$ Regina $\% 20$ Firmino.pdf 